\title{
REEs and trace elements characteristics of scheelite from the Mesozoic W-deposits in East Asia: Geochemical indicator of $W$ - mineralization mechanism
}

\author{
WOOHYUN CHOI ${ }^{1}$, YUNGOO SONG ${ }^{1}$, CHANGYUN

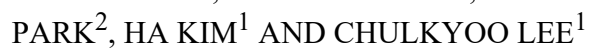 \\ ${ }^{1}$ Yonsei University \\ ${ }^{2}$ KIGAM \\ Presenting Author: woohyun16@yonsei.ac.kr
}

Korea once held major role of tungsten producer during mid$20^{\text {th }}$ century, because of the Sangdong W-deposit located in South Korea. China manufactured almost $60 \%$ of world's tungsten production until recently, because of Mesozoic Wdeposits in South China region. By reviewing papers about insitu trace element and REE studies of scheelite from the Mesozoic W-deposits in East Asia, common features about Wmineralization mechanisms could be found at different deposit environments.

Major factors that affect the mineralization mechanisms of scheelite are temperature $(\mathrm{T})$, pressure $(\mathrm{P})$, redox condition, compositions of magmatic fluid, geological setting of host rock, fluid-rock interaction ratio, and alterations, etc. Each factor is related with others closely and controlled by ore-forming processes. By its occurrence, scheelite can be largely subdivided into 'Massive type' and 'Vein type'. Massive type scheelite mainly appears at skarn deposits. During the prograde stage, high-T and constant fluid infiltration favors open system, and scheelite is formed by batch mineralization mechanisms from abundant magmatic fluid. Relatively oxidized condition results into majority of oxide minerals, mainly silicate minerals of skarn deposits (i.e. garnet, diopside, wollastonite, etc). Scheelite inherits trace element characteristics of granitic source, generally shows LREE enriched inclined patterns with negative $\mathrm{Eu}$ anomaly. In contrast, vein type scheelite mainly appears at veinlet-disseminated W-deposits and porphyry W-Mo deposits. They are generally formed during retrograde stage, lower-T with restricted fluid source after dilution. With little fluid-rock interaction at closed system, fractional crystallization takes place as a major mineralization mechanism. Mineral chemistry itself holds major role during REE substitution, initiating from MREE enriched M-type tetrad pattern and shifting into MREE depleted W-type tetrad pattern as mineralization proceeds. Relatively reduced condition results into scarce oxide minerals and abundant sulfide minerals such as pyrite, molybdenite and sphalerite. This type scheelite is also relatively pure with $\mathrm{W}$ content than the massive type one.

Using these common features of REEs and trace element geochemistry in scheelite, we tried to establish the classification protocols of scheelite. This will make ease to define the type of scheelite in the future exploitation of W-deposits, by providing the geochemical data and the ore-forming mechanisms. 